\title{
A Permanent Hair Loss in a Patient with Hypersensitivity to Intralesional Triamcinolone Injection
}

\author{
Young In Lee, Minseok Lee, Sewon Lee ${ }^{1}$, Do Young Kim \\ Department of Dermatology and Cutaneous Biology Research Institute, Yonsei University College of Medicine, ${ }^{1}$ Yonsei Leeand Skin Clinic, \\ Seoul, Korea
}

Despite multiple possible side effects, mesotherapy with a diverse mixture of unapproved products has been performed for the treatment of hair loss. In this case report, we present a rare case of permanent hair loss due to an allergic reaction from a mesotherapy mixture including triamcinolone acetonide. The patient showed a positive intradermal allergic skin test result for triamcinolone and therefore was diagnosed with scarring alopecia due to delayed type IV hypersensitivity to corticosteroid. This case study suggests that dermatologists should always be fully aware that both IgE-mediated and non-IgE-mediated hypersensitivity reactions from the corticosteroids as well as their mesotherapy excipients are possible in an effort to prevent irreversible adverse event from the mesotherapy. (Ann Dermatol 31(2) 217 220, 2019)

\section{-Keywords-}

Alopecia, Delayed hypersensitivity, Intralesional injections, Mesotherapy, Triamcinolone acetonide

\section{INTRODUCTION}

Mesotherapy has been widely applied in the treatment of

Received January 26, 2018, Revised April 4, 2018, Accepted for publication April 11, 2018

Corresponding author: Do Young Kim, Department of Dermatology and Cutaneous Biology Research Institute, Yonsei University College of Medicine, 50-1 Yonsei-ro, Seodaemun-gu, Seoul 03722, Korea. Tel: 82-22228-2083, Fax: 82-2-393-9157, E-mail: dykim@yuhs.ac ORCID: https://orcid.org/0000-0002-0194-9854

This is an Open Access article distributed under the terms of the Creative Commons Attribution Non-Commercial License (http://creativecommons. org/licenses/by-nc/4.0) which permits unrestricted non-commercial use, distribution, and reproduction in any medium, provided the original work is properly cited.

Copyright (c) The Korean Dermatological Association and The Korean Society for Investigative Dermatology alopecia, despite the lack of data regarding its potential adverse effects. Here, we present a case of permanent hair loss on injection sites due to a delayed type IV hypersensitivity reaction from a mesotherapy mixture that includes triamcinolone acetonide. This report highlights the possible risk of mesotherapy as a treatment modality for hair loss.

\section{CASE REPORT}

A 26-year-old woman with a history of female pattern alopecia presented to the dermatology clinic with edema, erythema, and numbness on her entire face after her first intralesional injection on the scalp of a mesotherapy mixture at a private clinic (Fig. 1). She was healthy with no past medical history or atopic disease. According to her medical records from the clinic, a painful edema and redness on her forehead developed on the day after the injection and later extended downward to her entire face. Edema and pain persisted for more than a week, and finally atrophic scars with crusts were formed at each injection site (Fig. 2). An intradermal allergic skin test for possible culprit agents was performed, and a positive reaction to $0.25 \mathrm{ml}$ triamcinolone acetonide (Dongkwang Pharm, Seoul, Korea) at the concentration of $10 \mathrm{mg} / \mathrm{ml}$ after 24 hours was identified (Fig. 3). The patient was diagnosed with alopecia due to a delayed hypersensitivity reaction to intralesional triamcinolone acetonide injection. Our clinic prescribed treatment with $3 \%$ topical minoxidil and intermittent non-ablative fractional laser therapy for the regeneration of the scalp dermis, but no sufficient improvement was noticed. We received the patient's consent form about publishing all photographic materials. 

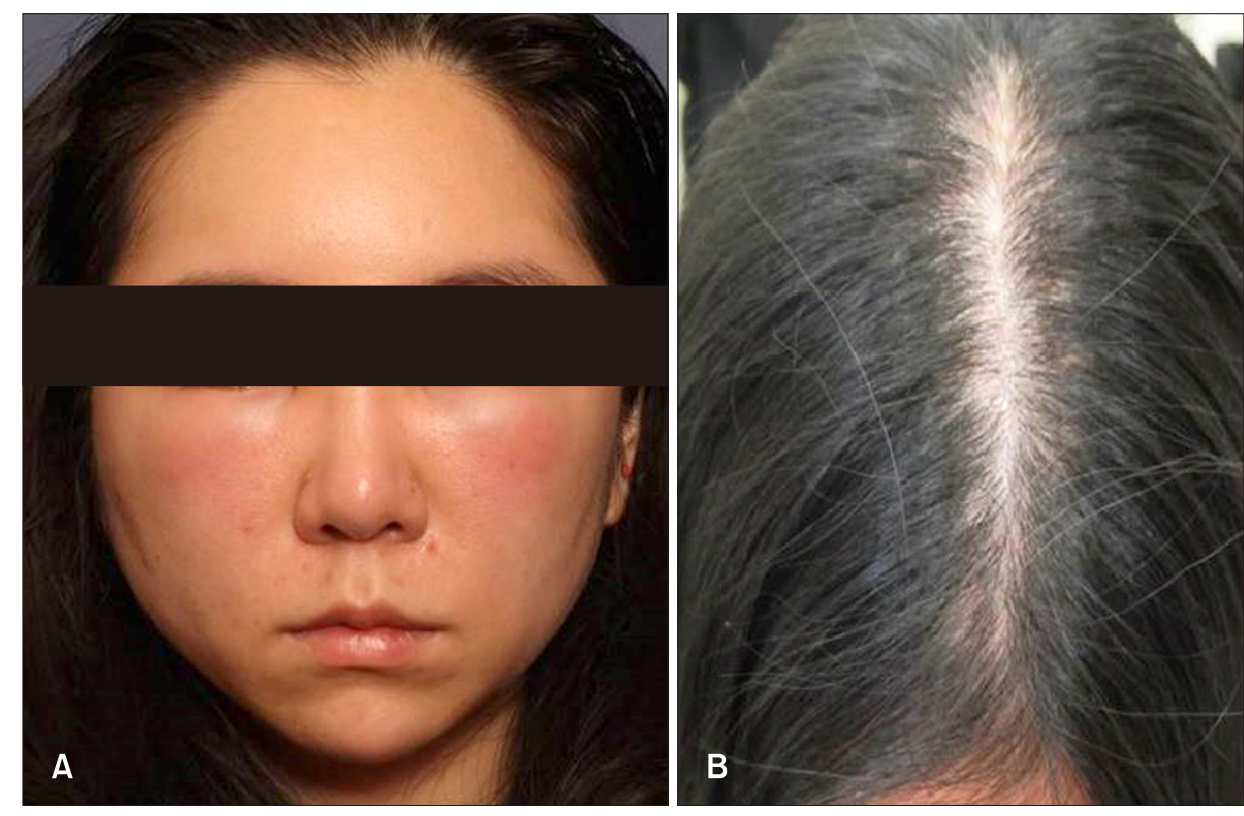

Fig. 1. Initial photographs of hypersensitivity reaction. Swelling on (A) face and (B) scalp developed after intralesional injection of the mesotherapy mixture.

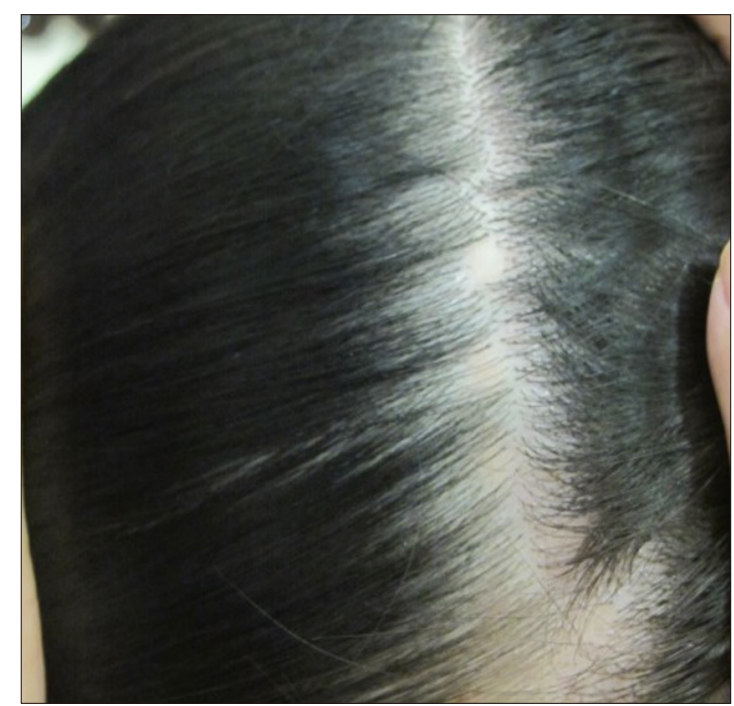

Fig. 2. A permanent hair loss shown at each intralesional corticosteroid injection site 1 month after the injection.

\section{DISCUSSION}

In contrast to the extremely frequent application of corticosteroids in many dermatologic diseases, the reported incidence of allergic reactions to these compounds is relatively uncommon ${ }^{1}$. Recently, however, the adverse events from the use of corticosteroids are increasingly recognized worldwide as a problem with considerable clinical importance. Both type I and type IV hypersensitivity reactions have been reported following exposure to corticosteroids ${ }^{2}$. Especially, the allergic contact dermatitis after the topical application of corticosteroids is the most commonly ob-

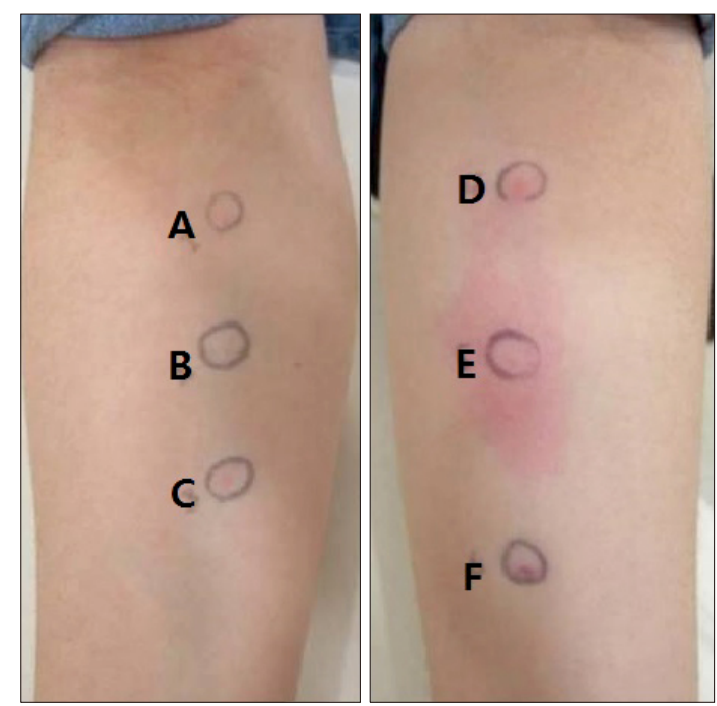

Fig. 3. Intradermal allergic skin test results showed positive reaction to $10 \mathrm{mg} / \mathrm{ml}$ triamcinolone acetonide: $\mathrm{A}, 100,000: 1 \mathrm{mix}-$ ture of $2 \%$ lidocaine +epinephrine; $\mathrm{B}, 2: 1$ mixture of normal saline $+\mathrm{NaHCO}_{3} ; \mathrm{C}$, normal saline $(0.9 \%$ sodium chloride); $\mathrm{D}$, antibiotics (lincomycin); E, 8:1 mixture of normal saline +10 $\mathrm{mg} / \mathrm{ml}$ triamcinolone acetonide; $\mathrm{F}, 5 \mathrm{mg} / \mathrm{ml}$ dexamethasone.

served hypersensitivity reaction, occurring in $4 \% \sim 5 \%$ of the population ${ }^{3}$.

Corticosteroids are also known to cause sensitization when used systemically, albeit this mode of sensitization is much more rare ${ }^{4}$. The prevalence of IgE-mediated, type I hypersensitivity reactions to systemic corticosteroids is reported to be approximately $0.3 \%{ }^{5}$. One of the earliest reports of the immediate type I reaction to systemic corti- 
costeroids described urticaria, angioedema, and bronchospasm after injections of corticosteroids in 20 of 2,256 patients $^{6}$.

A type IV hypersensitivity reaction to systemic and intralesional steroids presents typically as a generalized dermatitis or an exanthematous eruption, occasionally with blisters and purpuras ${ }^{7}$. Bircher et al. ${ }^{8}$ reported a delayed hypersensitivity to the oral administration of prednisone, inducing a generalized exanthem in the patient. Räsänen and Hasan ${ }^{3}$ also documented delayed hypersensitivity reactions to oral or intralesional corticosteroids in five patients, who developed diffuse erythema in a few to 24 hours after patch or intradermal skin tests.

There are 5 classes of structurally distinct corticosteroids, termed as class A, B, C, D1, and D $2^{9,10}$. These groups were defined according to substitutions on the corticosteroid structure and clinical characteristics. However, less is known about the classification and cross-reactivity pattern of the less common reactions following systemic administration of corticosteroids ${ }^{11}$. Our patient developed marked edema and erythema a few hours after the intralesional injection of triamcinolone acetonide, which belongs to the class B corticosteroids. We performed an allergic intradermal skin test for suspected drugs, including triamcinolone, the excipients $(100,000: 1$ mixture of $2 \%$ lidocaine/epinephrine, sodium bicarbonate, and $0.9 \%$ sodium chloride), antibiotics (lincomycin), and dexamethasone. After 24 hours, the patient presented with a positive intradermal skin test result solely at the triamcinolone site. Although a strong positive reaction to triamcinolone was noted, the intradermal skin test for dexamethasone, which belongs to the class $\mathrm{C}$ corticosteroids, was negative. This result supports the recent study on reaction patterns to corticosteroids, which indicated that reactivity to only one type of corticosteroid is much more common than reactivity to multiple types $^{12}$. Therefore, even though a patient reports no adverse events with previous steroid use, a dermatologist should still consider the possibility that the patient may undergo a hypersensitivity reaction to other types of steroids.

Several previous reports on triamcinolone acetonide hypersensitivity have reported that the culprit agent could be not only the corticosteroid itself but also its excipients, such as carboxymethylcellulose, benzyl alcohol, and polysorbate $80^{13-15}$. As the limitation to our study, we did not extensively analyze the excipients added to the triamcinolone mesotherapy mixture. It is crucial to perform allergologic testing of individual pharmaceutical excipients as well, since allergic reactions are not purely caused by the active pharmaceutical constituents.

In conclusion, our report presents a rare case of perma- nent hair loss following a severe type IV delayed hypersensitivity reaction to intralesional triamcinolone acetonide as part of a mesotherapy mixture. Although multiple side effects have been reported, mesotherapy with a diverse mixture of unapproved products has gained popularity for the treatment of alopecia ${ }^{16}$. To prevent irreversible side effects, physicians should always be fully aware that both IgE-mediated and non-IgE-mediated hypersensitivity reactions from the corticosteroids or their mesotherapy mixtures are possible. Especially, patients with atopic disease or previous history of drug allergy should be considered for testing to the corticosteroid as well as the excipients, because patterns of hypersensitivity reactions to mesotherapy are not fully uncovered at this point.

\section{CONFLICTS OF INTEREST}

The authors have nothing to disclose.

\section{ORCID}

Young In Lee, https://orcid.org/0000-0001-6831-7379

Minseok Lee, https://orcid.org/0000-0002-1886-489X

Sewon Lee, https://orcid.org/0000-0002-6675-6180

Do Young Kim, https://orcid.org/0000-0002-0194-9854

\section{REFERENCES}

1. Laisuan W, Wongsa C, Dchapaphapeaktak N, Tongdee M, Chatmapanrangsee J, Rerkpattanapipat T. Anaphylaxis following intralesional triamcinolone acetonide (Kenacort) injection. Asia Pac Allergy 2017;7:115-118.

2. Laberge L, Pratt M. Immediate and delayed hypersensitivity to systemic corticosteroids: 2 case reports. Dermatitis 2012; 23:288-290.

3. Räsänen L, Hasan T. Allergy to systemic and intralesional corticosteroids. Br J Dermatol 1993;128:407-411.

4. Saff DM, Taylor JS, Vidimos AT. Allergic reaction to intralesional triamcinolone acetonide: a case report. Arch Dermatol 1995;131:742-743.

5. Comaish S. A case of hypersensitivity to corticosteroids. Br J Dermatol 1969;81:919-925.

6. Kilpiö K, Hannuksela M. Corticosteroid allergy in asthma. Allergy 2003;58:1131-1135.

7. Browne F, Wilkinson SM. Effective prescribing in steroid allergy: controversies and cross-reactions. Clin Dermatol 2011; 29:287-294.

8. Bircher AJ, Bigliardi P, Zaugg T, Mäkinen-Kiljunen S. Delayed generalized allergic reactions to corticosteroids. Dermatology 2000;200:349-351.

9. Coopman S, Degreef H, Dooms-Goossens A. Identification of cross-reaction patterns in allergic contact dermatitis from topical corticosteroids. Br J Dermatol 1989;121:27-34.

10. Matura M, Goossens A. Contact allergy to corticosteroids. 
Allergy 2000;55:698-704.

11. Baeck M, Goossens A. Immediate and delayed allergic hypersensitivity to corticosteroids: practical guidelines. Contact Dermatitis 2012;66:38-45.

12. Pratt MD, Mufti A, Lipson J, Warshaw EM, Maibach HI, Taylor JS, et al. Patch test reactions to corticosteroids: retrospective analysis from the North American Contact Dermatitis Group 2007-2014. Dermatitis 2017;28:58-63.

13. Montoro J, Valero A, Elices A, Rubira N, Serra-Baldrich E, Amat $\mathrm{P}$, et al. Anaphylactic shock after intra-articular injection of carboxymethylcellulose. Allergol Immunopathol (Madr)
2000;28:332-333.

14. Al Hadithy A, van Maaren $M$, Vermes A. Anaphylactic reactions following Kenacort- $A^{\circledR}$ injection: carboxymethylcellulose is involved once again. Contact Dermatitis 2011; 64:179-180.

15. Bigliardi PL, Izakovic J, Weber JM, Bircher AJ. Anaphylaxis to the carbohydrate carboxymethylcellulose in parenteral corticosteroid preparations. Dermatology 2003;207:100-103.

16. Duque-Estrada B, Vincenzi C, Misciali C, Tosti A. Alopecia secondary to mesotherapy. J Am Acad Dermatol 2009;61: 707-709. 